\title{
A Study on the Application of Continuing Education Mode in College English Teachers in Internet+ Era
}

\author{
Zhifeng Nie \\ Tourism and Culture College of Yunnan University Lijiang, Yunnan \\ 674199
}

\begin{abstract}
With the rapid development of "Internet + " era, a diversified mixed teaching model and interactive learning environment such as MOOC and flipped class have been formed under the support of modern information technology such as Internet and intelligent equipment. These changes have contributed to the development of college English Teaching methods, learning methods, the role of teachers and other challenges and opportunities. In the past, English teachers, as the professors of basic English courses in colleges and universities, can only consolidate the basic position of English and play a positive role in the overall education of colleges and universities. Based on the present situation of continuing education of college English teachers, this paper discusses the urgent needs of college English teachers to carry out continuing education in combination with the investigation and research. On the basis of this, the paper analyzes deeply the development trend of continuing education of college English teachers. At last, it puts forward the mode selection of the continuing education of college English teachers, and makes full use of "Internet +", which has a certain reference significance in the construction of teaching staff, the effective adaptation to the different needs of students, enhancement of the teaching level of English teachers, and the reform of college English teaching. Key words: demand; colleges and universities; English teachers; continuing education; mode selection

As a basic course of higher education, college English plays an important role in the teaching and research work of colleges and universities. The level of English teachers' professional knowledge plays a key role in the development of English teaching. At present, Chinese college students have different needs for
\end{abstract}


English basic courses, which requires English teachers to actively adapt to the new situation and tasks, to grasp the students' psychological cognition and learning interest, and to constantly improve their teaching level by making full use of modern teaching technology and English teaching combined with the MOOC, flipped class, making the "Internet + education" has developed.

\section{First, the current situation of continuing education of college English teachers in China}

Teacher continuing education refers to a process of training which is systematic, continuing and specialized taken to the difficulties and problems encountered by teachers in the teaching work according to the different direction of teachers' professional development and their teaching subjects under the tenacity education philosophy. Continuing education is an important component of teacher education, which plays an important role in optimizing teachers' resources and improving the quality of teachers. The United States well-known education scholar Dr. Freeman pointed out: strengthening the training of teachers is a job which is more important in any education system than the optimization of teaching methods, improving curriculum design and content. Continuing education as a a continuing, systematic, tenured system of education is more important than the education that teachers receive during their studies. Even in a sense, the extent of continuing education can determine the success factor of the teacher's career. At the same time, he also believed that the cultivation of college English teacher education is a starting point is not the end of the education process. This education depends largely on the teachers themselves to do a good job of self-education motivation. [1] The English teachers in the training process is often only pay attention to form and diploma, ignoring the process and effect of learning and education is not conducive to the development of quality education. The survey found that many college English teachers to participate in on-the-job education and training as a title promotion, a higher degree, a means, often based on the original bachelor's degree by participating in other professional learning, supplemented by a few foreign language learning, so as to obtain a master's or doctoral degree, for their future work to lay the foundation for the expansion of job space. The effect of the multidisciplinary talents and the English proficiency of the English teachers is not obvious.

\section{Second, the current needs of strengthening the continuing education of college English teachers}

In recent years, with the expansion of the scale of the university and the enrollment of English teachers, teachers are seriously inadequate. Especially with the continuous development of our economy and the reform of quality education, and the development of "Internet + " new information revolution, teaching level 
and quality of English teachers are facing more and more pressure. In order to meet the demand of English teaching under the new era, to improve the teaching level of college English, to promote the reform of the basic course of English education in colleges and universities, to make full use of the Internet platform, it is urgent to establish a business elite, ability, high quality, pioneering spirit and innovative consciousness of English teacher team to improve teaching and research level.

1. At present, Chinese college English teachers are not satisfied with their teaching level generally, and have strong desire and demand for improving their business ability through continuing education. Although English teachers have a high sense of identity in their own occupation, to improve the teaching methods in the psychological cognitive level is very confused, and they lack of specific feasible measures and measures. The survey found that nearly 20\% of English teachers believe that as long as the English foundation will be able to satisfactorily complete the teaching task, while there are $68 \%$ of teachers believe that teaching English, learning English is not difficult to adhere to say, listen is good way to learn English courses. [2] This understanding is one-sided, indicating that many colleges and universities in China under the influence of traditional teaching ideas, modern teaching awareness and teaching methods, teaching model is simple and obsolete, which can not be well adapted to the current new demand situation. It is very important to take effective measures to improve the English teaching quality of college English teachers.

2. Teachers' professional needs and job functions are meet to needs of English teachers in the teaching work through continuous education to improve the teaching level, and constantly to improve the teaching methods, teaching autonomy, specialization, and better to adapt to the real needs. Teachers 'specialization is a trend in the development of education and teaching in the world. Although teachers' professional knowledge and standards have been greatly improved and even advanced in some respects, compared with the developed countries, Chinese English teachers' professional skills and the degree of specialization is still very clear gap. Only by continuously improving the existing teacher education and promoting the professionalization of English teachers can we continuously improve the quality of English education and teaching, improve the overall teachers of English teachers, and better meet the real needs of economic and social development.

3. The development of information technology requirements of English teachers to meet the real needs as the goal, to master and use of computers and other multimedia devices. At present, many colleges and universities curriculum multimedia teaching are the main means of teaching through multimedia. On one hand, it greatly reduces the burden on teachers, while classroom teaching is more intuitive, imageable, specific, to improve the efficiency of teaching and student learning effect. However, under the influence of the traditional educational idea and the characteristics of the subject, the English teachers are not familiar with the multimedia teaching operation and can not solve the problems in the practical operation timely and effectively. The results show that most English teachers do not have enough computer knowledge at the primary level. The development of 
English teachers is lagging behind. Foreign teachers have a strong targeted, scientific, and in the application of computer technology to deal with the ability to significantly higher, which rely on mobile Internet and intelligent equipment modernization, diversification and convenience of teaching methods, not only to adapt to "Internet +" era of college students learning characteristics and learning methods, but also to improve the efficiency and quality of college English teaching. Therefore, the application of modern teaching methods, such as computer and multimedia, urgently need college English teachers to do a good job in continuing education.

\section{3, the current trend of China's college English teachers to carry out continuing education}

College English teachers as a language teacher, to do a good job of basic education is a prerequisite for good English teaching. As a qualified English teacher, it is necessary to have reasonable and accurate pronunciation and the tone, proficient spoken language, rich vocabulary, correct sentences, grammar, good knowledge of other countries civilization, etiquette and customs. Only with the above-mentioned factors, can teachers stimulate students' interest in English teaching, and cultivate students' correct oral, phonetic, grammar, vocabulary, reading comprehension and appreciation ability. Through continuing education, our country has effectively solved the problem of serious decline in the basic skills of English education students since the expansion of college enrollment, has created a number of outstanding professional English teachers with rich theoretical knowledge, basic skills and solid foundation, and has improved the quality of teaching of English courses in colleges and universities. However, with the demand of the market economy and the establishment of the specialties, it is necessary for the English teachers not only to have the basic teaching quality but also to have the professional teaching ability, and to cultivate the compound talents through continuing education. Compound talents are the objective requirements of the development of the new century. With the integration of economic globalization, the times need more adaptable talents. English teachers can only adapt to the changing needs of the situation, through continuing education, to develop their own development plan, to choose their own training school.

In the current situation of the new educational needs, the overall quality of college English teachers not only include the ability to improve the professional disciplines, but also the ability to enhance the professional quality of teachers. However, at present, China's personnel training in the level, scale, structure is more single, fundamentally speaking, there is a clear difference between the academic education and career education. Professional subject education mainly refers to the English teachers' teaching level and scientific research ability. Professional quality of teachers is a systematic concept, including the professional ethics, professional spirit, cultural quality, scientific quality, 
psychological quality and professional skills, and many other aspects of the coordinated development. [3] The professional quality of English teachers is an important aspect of whether the ability to have skilled use of computers, multimedia English teaching and the ability to carry out English research. Emphasis on this point is that many college English teachers because of lack of computer skills, without the systematic and specialized training, the teaching process can not be a good problem to solve. For example, the background of the Internet era, the emergence of flipped class emerging teaching model, the knowledge is required to teach students to watch the teaching videos completed in class, through various forms of teaching in the classroom to complete the internalization of knowledge, which optimizes the traditional learning process knowledge transfer and knowledge internalization of the two stages, so these is an urgent need for college English teachers to master the relevant technology.

\section{4, the current mode of strengthening the continuing education of college English teachers in China}

The teaching mode of traditional teaching cooperation has a long history, although it has its limitations, it is still widely used. In this model, the trainee receives new instruction from the instructor. From the perspective of the continuing education development of English teachers, this model is no longer respected, but the teaching concept of this model is still applied to the classroom teaching cooperation between teachers and students. With the advent of "Internet +" era, the rise of MOOC, flipped class, mobile learning platform, teachers are guiding students to learn and to subvert the dominant position of teachers. Teachers will help students to make full use of Internet resources, to enhance access to resources, to make use of resources, and to deal with information application knowledge, so teachers need to constantly improve their personal information technology capabilities. In this Internet model, the relationship between teachers and students is not a true sense of the relationship between teachers and students, but a cooperative relations, that is students are teachers. When there is a knowledgeable, professional and noble professional experts, it is good to fulfill the theoretical knowledge of students learning and professional competence. Students can learn from them to enrich their own experience, to improve their self-cultivation and to have the opportunity to get along with such an expert instructor, which for students is a rare opportunity and experience. In this mode of education, teachers not only teach students the theoretical knowledge, but also impart new ideas and methods to enable students to static learning methods in the dynamic learning process, so that their own theoretical knowledge of learning and other areas access to greater gains and increase.

This mode of education for students of the professional characteristics and needs of their own, focused, targeted to the students to teach theoretical knowledge, combined with the practical application of theory and practice to achieve the organic integration. Therefore, this kind of education model is also 
called the pure sense of the theory of learning-based education model. Fundamentally, this is also a traditional educational model, and has many similarities with the first kind of education model. The model is widely used, mainly because it can be more objective and impartial. The trainers will be based on the actual situation, the relevant knowledge to impart to students or in the teaching process to make appropriate adjustments. College English curriculum as a university sophomore course, requires English teachers must have a strong theoretical knowledge of the professional, which is to adapt to the basic premise of effective demand.

Case teaching is a common mode of education in continuing education, including discussion and analysis. The model is characterized by a typical analysis of a general summary of the general characteristics of disciplines. As a college English teacher needs in the teaching practice will get experience and related viewpoints to establish a typical case. With the actual needs of economic and social development, college English teachers in continuing education in the use of case teaching model is very meaningful, the study of student knowledge will play a significant role in promoting the improvement of teaching skills and teaching knowledge. On one hand, English teachers should actively break through the limitations of traditional education, to carry out continuing education as the realization of teachers who should take the initiative to adapt to the new situation, new demands, strengthen theoretical knowledge learning, automatic updating of educational ideas and educational models. On the other hand, they should consider the education as a career to fulfill the integration of education, autonomy, and professionalism.

In the above three models of continuing education, we can see that any single mode of education has its own shortcomings and shortcomings, in the continuing education of college English teachers rely on a model is not possible to enable students to improve the basic knowledge. Comprehensive education model is a systematic model for the continuous education and training of college English teachers. It can enable the students to gain the knowledge that is conducive to the improvement of their own teaching level through specific activities and personal experiences in a relatively short period of time. Therefore, in order to comprehensively improve the level of computer operation of college English teachers, the relevant state ministries and commissions actively carry out information technology training for English teachers, adopt various effective measures to improve the enthusiasm of English teachers in applying modern information technology like the computer, multimedia and other skilled use to the actual teaching and research work.

\section{References}

[1] Jia Aiwu. American Foreign Language Teacher Education and Professional Qualification Standards Policy Research [J]. Foreign Language .2006, (2): 86-88 [2] Huang Yuanshen. The 21st Century Compound English Talents [J]. Education and occupation. 2001, (1): 55-56 
[3] Nan Zuomin. Cultural English Major Bottlenecks and Countermeasures [J].

Foreign Language Community. 2005, (5): 101-102 